\title{
Chest tube drainage versus needle aspiration for primary spontaneous pneumothorax: which is better?
}

\author{
Chengdi Wang $^{1 *}$, Mengyuan Lyu ${ }^{2 *}$, Jian Zhou $^{3}$, Yang Liu ${ }^{4}$, Yulin Ji ${ }^{1}$ \\ ${ }^{1}$ Department of Respiratory and Critical Care Medicine, ${ }^{2}$ Department of Laboratory Medicine, ${ }^{3}$ Department of Thoracic Surgery, ${ }^{4}$ Department of \\ Vascular Surgery, West China Medical School/West China Hospital, Sichuan University, Chengdu 610041, China \\ Contributions: (I) Conception and design: C Wang, M Lyu, Y Ji; (II) Administrative support: Y Ji; (III) Provision of study materials or patients: \\ C Wang, M Lyu; (IV) Collection and assembly of data: J Zhou, Y Liu; (V) Data analysis and interpretation: M Lyu, J Zhou; (VI) Manuscript writing \\ and revision: All authors; (VII) Final approval of manuscript: All authors. \\ *These authors contributed equally to this work. \\ Correspondence to: Yulin Ji. No. 37, Guoxue Alley, Chengdu 610041, China. Email: jiyulinscu@sina.cn.
}

\begin{abstract}
Background: Needle aspiration and chest tube drainages are two main treatments for primary spontaneous pneumothorax (PSP). However, the application of needle aspiration or chest tube drainages has not reached a consensus. The aim of this study is to compare the needle aspiration with chest tube drainages in patients suffering with PSP and therefore help offer suggestions for clinical practice.

Methods: We searched literatures from PubMed, OVID and Web of Science from their inception to June 30, 2017. Continuous and dichotomous outcomes were expressed by weight mean difference (WMD) and risk ratio (RR) respectively, and each with $95 \%$ confidence intervals (CIs). We used the fixed effect or random effect model to perform quantitative synthesis.

Results: A total of 6 RCTs recruiting 458 participants were included in our analysis. On the basis of the six studies, our results indicated that compared with chest tube drainage applying needle aspiration shortened the hospital stay (WMD: -1.67 days; 95\% CI: -2.25 to $1.08 ; \mathrm{P}<0.001$ ) and decreased hospitalization rate (RR: 0.40 ; 95\% CI: 0.22-0.75; $\mathrm{P}=0.004)$. However, there was no difference regarding immediate success rate (RR: 1.01; 95\% CI: 0.70-1.46; P=0.96) and one-year recurrence rate (RR: 0.89; 95\% CI: 0.58-1.38; P=0.61).

Conclusions: In the light of this present research, it is necessary to apply needle aspiration into treating PSP to reduce hospitalization rate and shorten hospital stay. However, the two treatments have no significant difference with respect to immediate success rate, one-year recurrence rate, one-week success rate, three-month recurrence rate or complication rate.
\end{abstract}

Keywords: Spontaneous pneumothorax (SP); chest tube drainage; needle aspiration

Submitted Mar 21, 2017. Accepted for publication Jul 24, 2017.

doi: $10.21037 /$ jtd.2017.08.140

View this article at: http://dx.doi.org/10.21037/jtd.2017.08.140

\section{Introduction}

Spontaneous pneumothorax (SP) is a worldwide health problem $(1,2)$. The overall hospital admission rates for SP in the UK have been reported as 16.7/100,000 for men and $5.8 / 100,000$ for women, with corresponding mortality rates of $1.26 /$ million and $0.62 /$ million per year between 1991 and 1995 (3). Pneumothorax is defined as the presence of air in the pleural cavity, between the lung and the chest wall $(4,5)$ and is classified as spontaneous, traumatic, and iatrogenic pneumothorax (6). Spontaneous pneumothorax can also be classified as primary spontaneous pneumothorax (PSP) and secondary spontaneous pneumothorax (SSP) (7). PSP develops usually following bullae ruptures without any underlying pulmonary diseases, while secondary pneumothorax is usually caused by rupture of damaged lung tissue, and appears primarily in patients diagnosed with pulmonary disease, such as pulmonary emphysema (8). 
Current treatments for pneumothorax include needle aspiration (9-11), chest tube drainage $(12,13)$, videoassisted thoracic surgery (VATS) $(14,15)$ and open surgical interventions $(16,17)$. The needle aspiration could reduce the excessive air directly with a syringe through a needle, usually performed through the second or third intercostal space in the midclavicular line $(10,18)$. Clinically, when aspiration is unsuccessful, patients will be managed with chest tube drainage (19), which uses negative pressure to reduce excessive air. The chest tube drainage is usually placed in the anterior pleural space passing through the sixth intercostal space into the pleural opening, turned anteriorly and directed to the specific position of the pneumothorax, and then connected to a Heimlich valve or an underwater seal with or without continuous suction $(20,21)$. However, there has been a great controversy regarding the choice of treatments (22). The American College of Chest Physicians guidelines indicated that needle aspiration was to be rarely appropriate in any clinical circumstances (23). In contrast, the current British Thoracic Society (BTS) guidelines for the management of pneumothorax recommended simple aspiration as first-line treatment for all primary pneumothorax cases requiring intervention or therapy (24). Up to date, several researches have discussed this controversial problem but failed to reach definite consensus. Thus, it is meaningful to carry out this analysis and help present suggestions for clinical practice.

\section{Methods}

\section{Search strategy}

We searched studies in the PubMed, OVID and Web of Science from their inception to June 30, 2017 with the following terms: pneumothorax and chest tube, tube, chest drainage, drainage system, drainage, chest-tube, chest tubes or catheter and aspiration. The language was only restricted to English. And the references of relevant studies were also searched manually to identify potential eligible trials.

\section{Inclusion and exclusion criteria}

Included studies needed to: (I) be randomized controlled trails (RCTs); (II) research on patients suffering with PSP; (III) apply two different methods-needle aspiration and chest tube drainage independently.

Once the studies met one of the following criteria, they were excluded: (I) reviews, letters, animal experiments, conference abstracts and case reports; (II) patients had SSP or other underlying lung diseases; (III) the paper was not presented with English; (IV) some essential basic information was incomplete. Eligible studies were evaluated and identified by two independent reviewers according to the inclusion and exclusion criteria. Any disagreement was resolved carefully through discussion, and if necessary, the third researcher would adjudicate.

\section{Quality assessment}

Quality assessment is necessary for the eligible articles to ensure the accuracy of this analysis. With the guidance of the Cochrane Handbook for Systemic Reviews of Interventions, two independent investigators evaluated the risk of bias of including studies. Any difference was discussed carefully. The contents for evaluating the risk of bias including sequence generation and concealment of allocation (selection bias), blinding of participants and personnel (performance bias), blinding of outcome assessors (detection bias), incomplete outcome data addressed (attrition bias), free of selective reporting (reporting bias) and other bias.

\section{Data extraction and management}

Two authors independently extracted some data from eligible studies preliminarily, and any disagreement was solved with further discussion. The compared data included hospital stay, immediate success rate, one-year recurrence rate, hospitalization rate, complications rate, time of recurrence weeks and so on. While the basic data comprised the first author, publication year, countries, enrolled year, inclusion and exclusion criteria, sample size, chest tube drainage type, removal criteria, etc.

\section{Statistical analysis}

The risk ratio (RR) and weight mean difference (WMD) were measured to presented dichotomous and continuous outcomes, respectively. Meanwhile we calculated $\mathrm{p}$ value and $95 \%$ confidence intervals (CIs). If the $\mathrm{P}$ value $<0.05$, the results indicated statistical significance. Concerning the heterogeneity of these included studies, the Cochran's $\mathrm{Q}$ statistic and $\mathrm{I}^{2}$ statistics were performed. When $\mathrm{I}^{2}>50 \%$, we would choose random effect model in our analysis, otherwise fixed effect model. Furthermore, we performed the subgroup analysis to identify and explain the potential heterogeneity. We assessed publication bias by observing 


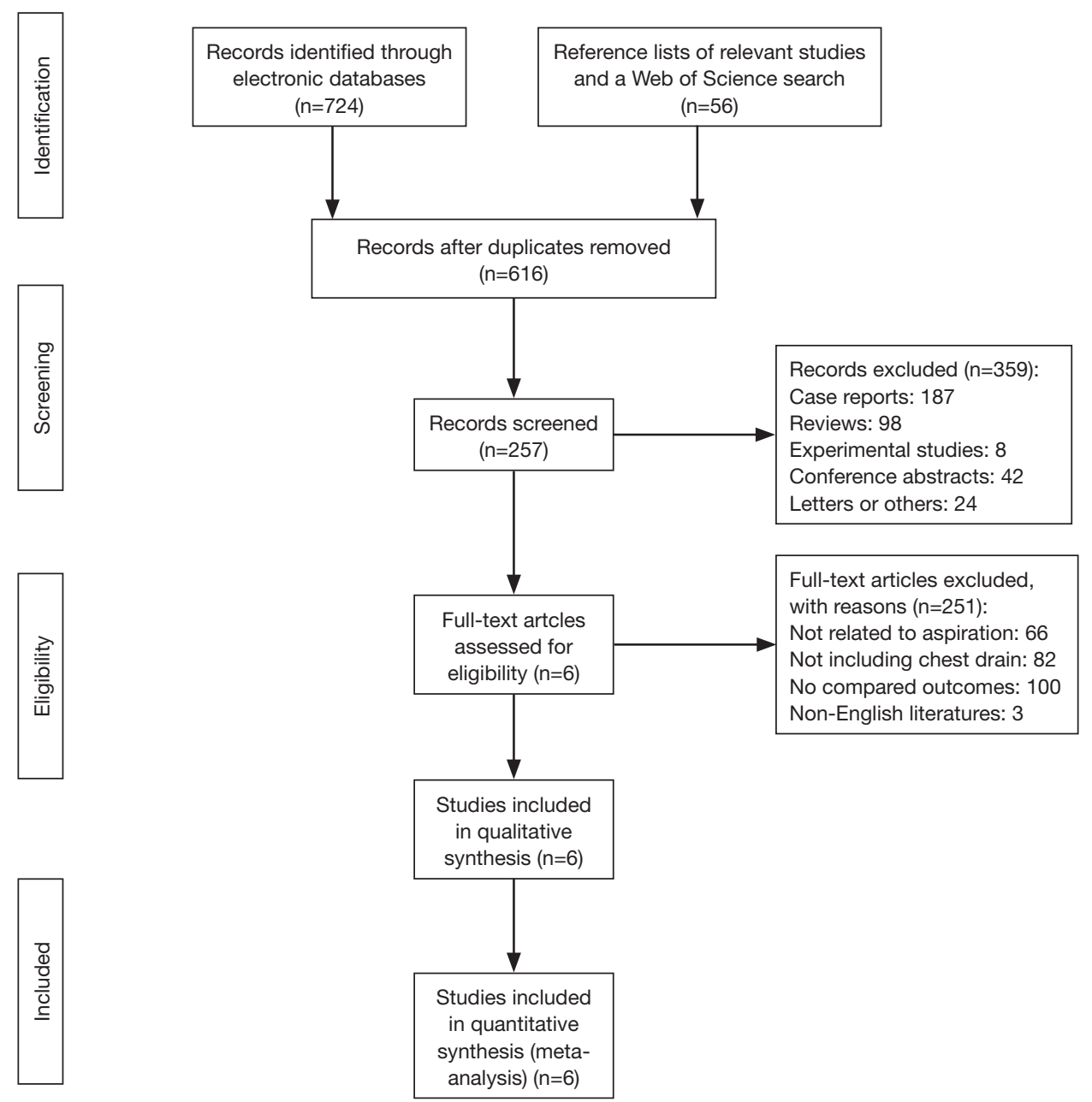

Figure 1 The PRISMA flow diagram of literature retrieval.

the funnel plots and performing Begg's test. We also performed sensitivity analysis to remove some low quality studies and repeated pooled analysis to ensure the accuracy of our analysis. All statistical analysis was performed by Review Manager V.5.3 (The Cochrane Collaboration, Software Update, Oxford, UK).

\section{Results}

\section{Studies characteristics}

A total of 780 articles were retrieved after literature search, and finally only 6 studies (25-30) enrolling 458 participants met our criteria. The included trials were published online between 1994 and 2017. The sample size of eligible studies ranged from 48 to 137 and the ethnicity included Asian and
Caucasian. The reported types of needle aspiration included 16F, 18F, 16G, 16-18G, and 12F, 16F, 20F and 28F were the major types of chest tube drainages. All the recruited patients suffered from PSP. The mean age of the participants applied with needle aspiration ranged from 24.38 to 40.5 , while the mean age of patients with chest tube drainages ranged from 23.5 to 40.9 . The outcomes of the included studies were presented with hospital stay, immediate success rate, one-year recurrence rate, hospitalization rate complications rate, etc.

The PRISMA flow diagram of literature retrieval is shown in Figure 1. The main characteristics of the included randomized controlled trials are presented in Table 1.

\section{Risk of bias}

Two independent investigators evaluated the risk of bias of 
Table 1 Main characteristics of the included randomized controlled trials

\begin{tabular}{|c|c|c|c|c|c|c|c|c|c|c|}
\hline Study & Sample & Country & $\begin{array}{l}\text { Enrolled } \\
\text { year }\end{array}$ & Pneumothorax & A. type & C. type & $\begin{array}{l}\text { A. age, } \\
\text { mean (SD) }\end{array}$ & $\begin{array}{l}\text { C. age, } \\
\text { mean (SD) }\end{array}$ & $\begin{array}{c}\text { A. } \\
\text { group }\end{array}$ & $\begin{array}{c}\text { C. } \\
\text { group }\end{array}$ \\
\hline Andrivet 1995 & 61 & France & NA & SP & $16 \mathrm{~F}, 18 \mathrm{~F}$ & $20 \mathrm{~F}$ & $32.0(16.0)$ & $33.0(13.0)$ & 33 & 28 \\
\hline Ayed 2006 & 137 & Kuwait. & 2001-2003 & PSP & $16 G$ & $20 \mathrm{~F}$ & $24.4(4.4)$ & $23.5(4.8)$ & 65 & 72 \\
\hline Harvey 1994 & 73 & Britain & NA & SP & $16-18 G$ & NA & $34.6(15.0)$ & $34.6(13.1)$ & 35 & 38 \\
\hline Thelle 2017 & 79 & Norwegian & NA & PSP & $16 G$ & $12-28 \mathrm{~F}$ & $40.5(21.5)$ & $40.9(19.5)$ & 42 & 37 \\
\hline
\end{tabular}

A, aspiration; C, chest drains; NA, unavailable; SP, spontaneous pneumothorax; PSP, primary spontaneous pneumothorax.

Table 2 Risk of bias assessment

\begin{tabular}{|c|c|c|c|c|c|c|c|}
\hline Study & $\begin{array}{l}\text { Sequence } \\
\text { generation }\end{array}$ & $\begin{array}{l}\text { Concealment } \\
\text { of allocation }\end{array}$ & $\begin{array}{l}\text { Blinding of } \\
\text { participants and } \\
\text { personnel }\end{array}$ & $\begin{array}{l}\text { Blinding of } \\
\text { outcome assessors }\end{array}$ & $\begin{array}{l}\text { Incomplete } \\
\text { outcome data } \\
\text { addressed }\end{array}$ & $\begin{array}{l}\text { Free of selective } \\
\text { reporting }\end{array}$ & $\begin{array}{l}\text { Other } \\
\text { bias }\end{array}$ \\
\hline Ayed 2006 & Low & Low & Low & Low & Low & Low & Low \\
\hline Harvey 1994 & High & Unclear & Low & Low & Unclear & Low & Low \\
\hline Noppen 2002 & Low & Low & Low & Low & Low & Low & Low \\
\hline Thelle 2017 & Low & Low & Low & Low & Low & Low & Low \\
\hline
\end{tabular}

the included studies. Andrivet [1995] had unclear risk of bias for sequence generation, concealment of allocation and low risk of bias for blinding of participants, personnel and outcome assessors, incomplete outcome data addressed, free of selective reporting and other bias. Ayed [2006], Noppen [2002] and Ho [2011] had low risk of bias for all aspects of bias we assessed. In terms of concealment of allocation, Andrivet [1995] and Harvey [1994] had unclear risk of bias. In our assessment, Harvey [1994] showed high risk of bias for sequence generation and unclear risk of bias for concealment of allocation and incomplete outcome data addressed. The graph of the risk of bias of the included studies is shown in Table 2, Figures 2,3.

\section{Hospital stay}

In six studies included, 225 participants were treated with needle aspiration compared with 233 to chest tube drainage. Five studies including 410 participants mentioned the hospital stay except Ho's research [2011]. With our analysis, we concluded that needle aspiration significantly shortened the hospital stay (WMD: -1.67 days; $95 \%$ CI: -2.25 to 1.08 ; $\mathrm{P}<0.001$ ) (Figure 4). As for the heterogeneity, we confirmed low heterogeneity with $\mathrm{I}^{2}=0 \%$. And there were no significant discoveries in the subgroup analysis for limited studies and low heterogeneity.

\section{Immediate success rate}

Four studies including 337 patients measured the immediate success rate. In our analysis, no significant difference were found between needle aspiration treatment and chest tube drainage (RR: 1.01; 95\% CI: 0.70-1.46; $\mathrm{P}=0.96$ ) (Figure 5). The same as the hospital stay, there were no significant findings in the subgroup analysis.

\section{One-year recurrence rate}

There were no significant difference regarding oneyear recurrence rate between the patients applied with needle aspiration and chest tube drainage (RR: 0.89; $95 \%$ CI: $0.58-1.38 ; \mathrm{P}=0.61$ )with analysis of three trials enrolling 


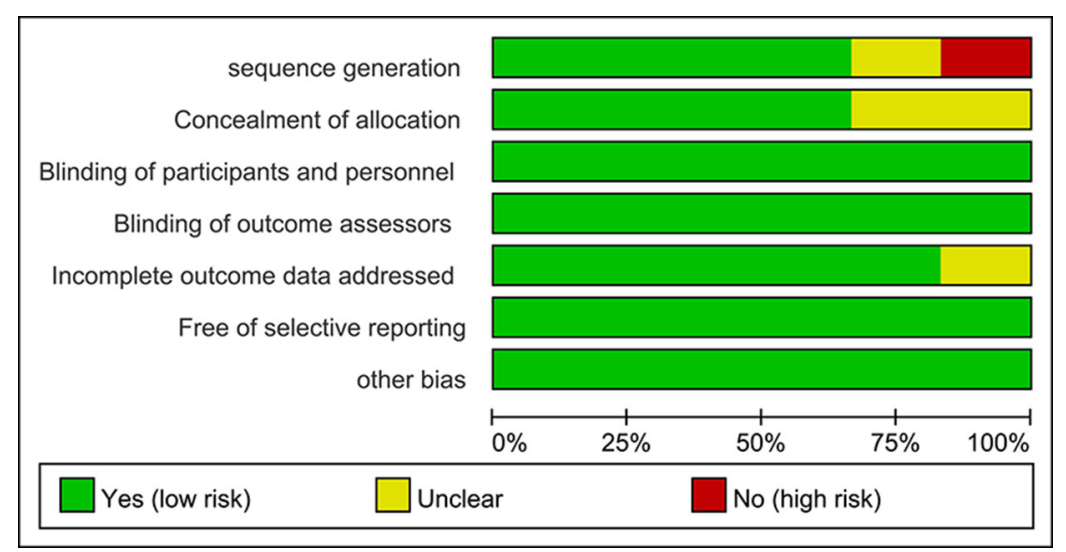

Figure 2 Graph of the risk of bias for the included studies.

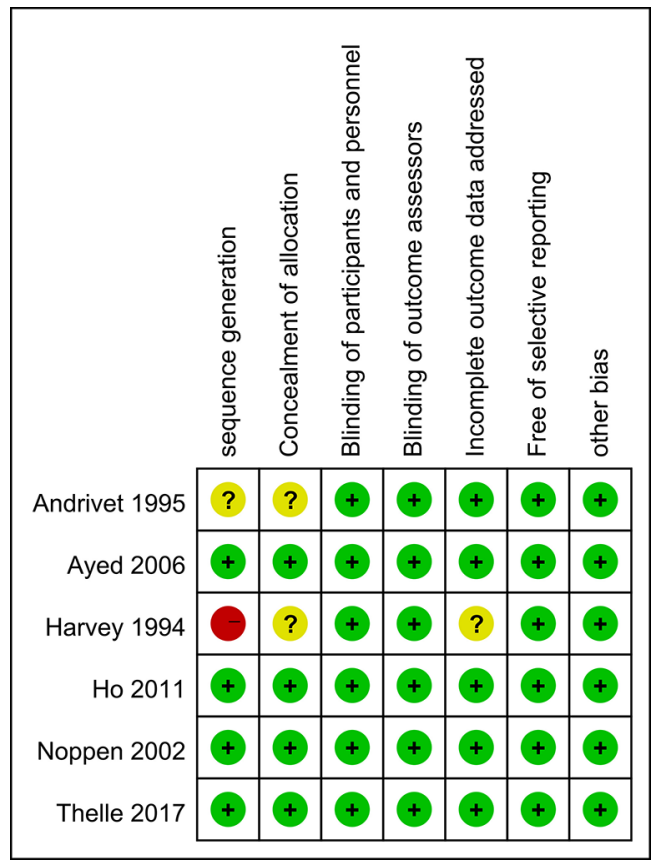

Figure 3 Graph of the risk of bias summary for the included studies.
262 patients (Figure 6). Low heterogeneity $\left(\mathrm{I}^{2}=0 \%\right)$ was identified. And subgroup analysis didn't get any meaningful findings.

\section{Hospitalization rate}

On the basis of 3 eligible trails included 245 subjects in total, we found needle aspiration group had lower hospitalization rate compared with chest tube drainage group (RR: 0.40; 95\% CI: 0.22-0.75; P=0.004) (Figure 7).

\section{Otber parameters}

To perform more comprehensive comparisons between the needle aspiration and chest tube drainage, we paid attention to the following parameters: one-week success rate, three-month recurrence rate, time of recurrence weeks, complications rate, the immediate complete retraction rate and total pain score. However, no significant difference was found. All of the main results of our analysis are shown in Table 3.

\begin{tabular}{|c|c|c|c|c|c|c|c|c|c|c|c|}
\hline \multirow[b]{2}{*}{ Study or Subgroup } & \multicolumn{3}{|c|}{ Experimental } & \multicolumn{3}{|c|}{ Control } & \multicolumn{2}{|c|}{ Mean Difference } & \multirow{2}{*}{\multicolumn{3}{|c|}{$\begin{array}{l}\text { Mean Difference } \\
\text { IV. Fixed. } 95 \% \mathrm{Cl}\end{array}$}} \\
\hline & Mean & SD & Total & Mean & SD & Total & Weight & IV. Fixed. $95 \% \mathrm{Cl}$ & & & \\
\hline Ayed 2006 & 1.85 & 3.9 & 65 & 4 & 2.9 & 72 & $25.4 \%$ & $-2.15[-3.31,-0.99]$ & -- & & \\
\hline Noppen 2002 & 3.4 & 1.6 & 27 & 4.5 & 2.7 & 33 & $28.2 \%$ & $-1.10[-2.20,0.00]$ & - & & \\
\hline Thelle A 2017 & 2.2 & 2.44 & 42 & 4.1 & 2.74 & 37 & $25.8 \%$ & $-1.90[-3.05,-0.75]$ & -- & & \\
\hline Total $(95 \% \mathrm{Cl})$ & & & 202 & & & 208 & $100.0 \%$ & $-1.67[-2.25,-1.08]$ & & & \\
\hline
\end{tabular}

Figure 4 Meta-analysis of the effect of chest tube drainage or needle aspiration for primary spontaneous pneumothorax on hospital stay (WMD). 


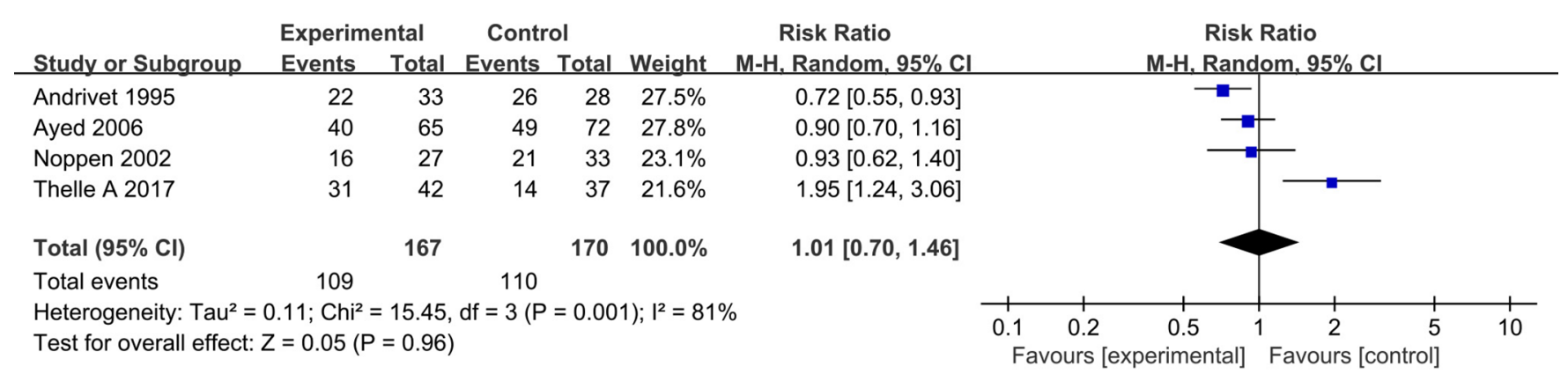

Figure 5 Meta-analysis of the effect of chest tube drainage or needle aspiration for primary spontaneous pneumothorax on immediate success rate (RR).

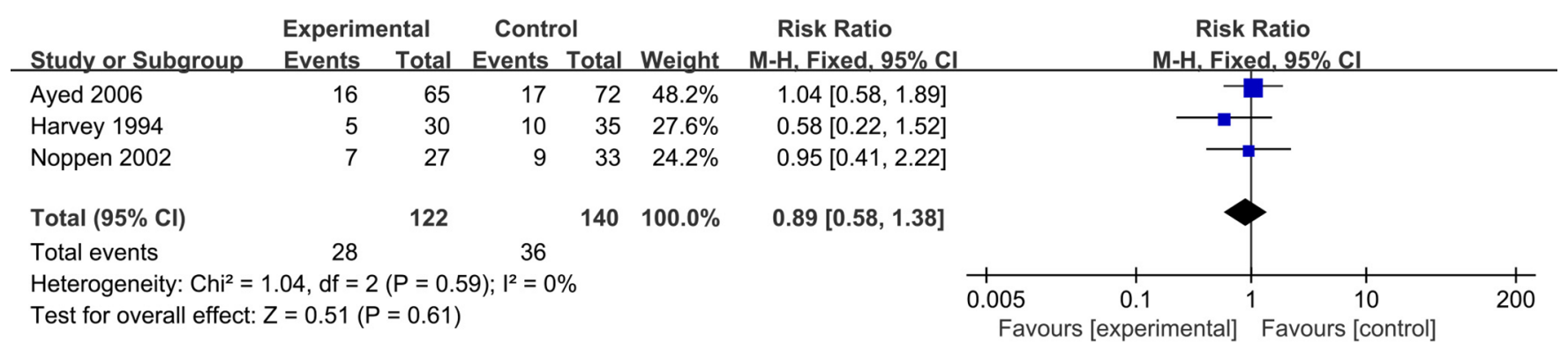

Figure 6 Meta-analysis of the effect of chest tube drainage or needle aspiration on one-year occurrence rate (RR).

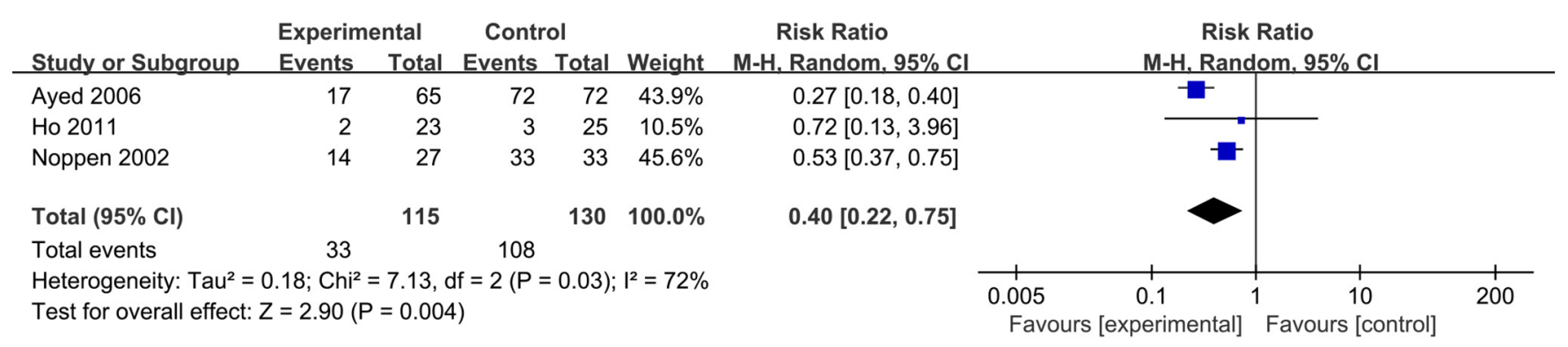

Figure 7 Meta-analysis of the effect of chest tube drainage or needle aspiration on hospitalization rate (RR).

\section{Sensitivity analysis and publication bias}

To discover potential heterogeneity, we performed sensitivity analysis. Through the symmetrical forest plots, we didn't find any potential and significant heterogeneity. Thus, it was not necessary to leave some low quality studies and repeat analysis of the remaining studies. Furthermore, no significant publication bias was identified by observing the funnel plots and performing Begg's test.

\section{Discussion}

We performed this present analysis to further assess the effects of needle aspiration and chest tube drainage on PSP patients. Compared with chest tube drainage, needle aspiration decreased hospital stay and hospitalization rate as the treatments for PSP. However, there was no statistical significance concerning immediate success rate, one-year recurrence rate, one-week success rate, three-month recurrence rate, time of recurrence weeks, complications rate, immediate complete retraction rate or total pain score.

Clinically, we usually used the hospital stay to evaluate the efficacy of specific therapies, which were related with cost and hospital performance $(31,32)$. Through analyses based on six studies, we concluded that needle aspiration 
Table 3 Main results of our analysis

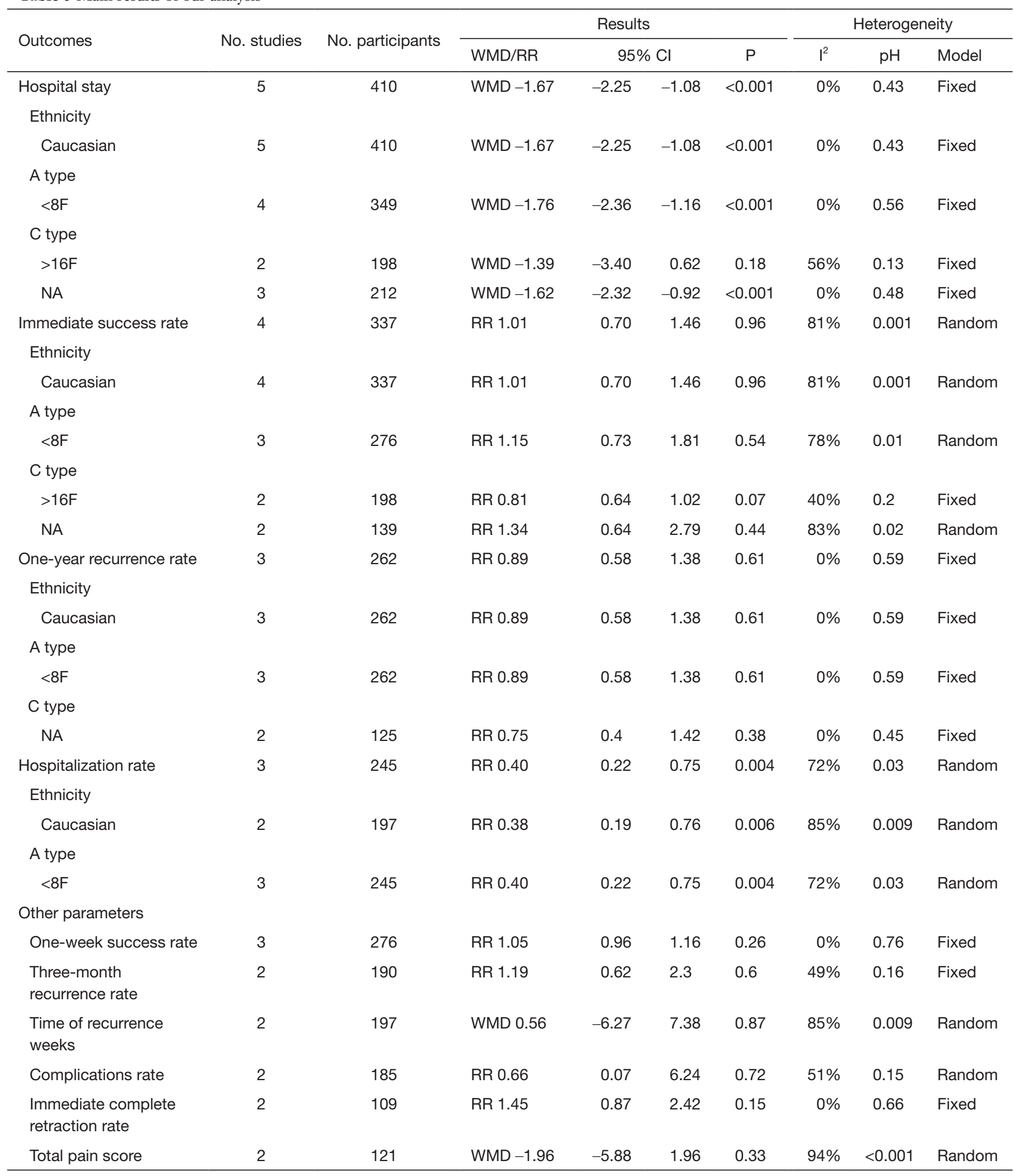

$\mathrm{A}$, aspiration; C, chest drains; NA, unavailable; RR, risk ratio; WMD, weighted mean difference; $\mathrm{Cl}$, confidence interval; $\mathrm{P}$, $\mathrm{P}$ value of overall effect; p. $\mathrm{H}, \mathrm{P}$ value of heterogeneity. 
reduced the hospital stay significantly. However, this conclusion was still controversial. Andrivet (25) found that there were no significant difference between patients allocated to needle aspiration and chest tube drainage. The size of sample and weakness of methodology might be the influence factors. To identify and assess the potential heterogeneity of included studies, we performed subgroup analysis according to the ethnicity, the catheter's types of needle aspiration and chest tube drainage. However, no significant and valuable difference were found.

Different studies had different definitions of immediate success rate, which was an essential parameter to evaluate the quality of therapy. Aye and his colleagues (26) defined it as complete or nearly complete lung expansion immediately after the procedure of needle aspiration and absence of air leak, complete lung expansion, and tube removal within 3 days after insertion of chest tube. However, it was defined as complete lung expansion immediately after 24 hours for needle aspiration, while complete lung expansion, absence of air leak, and chest tube removal within 3 days of insertion for chest tube in the Parlak et al.'s research (33). Our result showed no significant difference between the two groups, and this pooled outcome was consistent with Kaneda et al.'s report(7).

Recurrence was relevant to long-term survival quality and associated with treatment efficacy (34). For our research, we used one-year recurrence rate to evaluate the effects of needle aspiration and chest tube drainage with no significant difference found between the two groups.

The severity of pneumothorax decided whether to be hospitalized (35). When pneumothorax became pretty serious, it would require hospitalization to intervene. And hospitalization rate was always measured to assess the severity of diseases (36). It revealed that using needle aspiration had lower hospitalization rate than chest tube drainage for the patients suffering from PSP with analysis of the 3 included studies. Among the three articles, Ho et al. (28) held the contrary opinion that there was no statistically significant difference between two treatments. We found the participants in this trial were Asian, while the others were Caucasian. However, no significant difference was found in subgroup analysis. In addition, the enrolled samples were pretty small compared to others. These two different aspects might affect the final results.

As a clinical technique, needle aspiration was simple, effective, and acceptable to patients $(37,38)$. Irrespective of the size of pneumothorax, number of previous episodes, or whether the current condition was considered primary or secondary, needle aspiration would be recommended as an initial treatment for all spontaneous pneumothorax when intervention was necessary $(39,40)$. It had been used widely with its characteristics of easy operation, safety and less pain $(41,42)$. However the issue whether to apply needle aspiration for PSP had still remained controversial after consulting existing literatures. According to the current BTS guidelines, a flow chart for the treatment of PSP where "small" and "large" pneumothorax was classified based on the horizontal distance $<2$ or $>2 \mathrm{~cm}$ between the chest wall and the side margin of the collapsed lung, respectively (43). And in the BTS guidelines updated in 2010, it suggested that the choice of a $2 \mathrm{~cm}$ distance was made at the level of the hilum to measure the ratio of the lung to the hemithorax diameter (3). Needle aspiration was shown to be associated with reduced hospitalization rate and length of hospital stay (3). This was in agreement with the Australian guidelines (44). Furthermore, Nishiuma and his colleagues (45) held the view that needle aspiration should be considered as the first choice in the management of mild and moderate PSP ("mild" was defined as the pneumothorax cranial to the level of collarbone area; "moderate" referred to intermediate between mild and severe pneumothorax; and "severe" was defined as the pneumothorax with completely collapsed lung), opposite to the view of Kuester (46). Low success rate of needle aspiration was the shortcoming pointed out most frequently. For example, Courtney and his colleagues (47), who researched on the management of spontaneous pneumothorax in a hospital in Northern Ireland from 1994 to 1996, reported a low success rate of aspiration for pneumothorax with only 2 of 7 cases succeeded. Based on further analysis, we pointed out several possible reasons to explain the lower success rate of needle aspiration, one of which might be the technological level directly associated with operation success. Different procedures were performed to treat spontaneous pneumothorax by different doctors, which would impact the prognosis. Besides, patients were various in the severity of pneumothorax. Different severity of pneumothorax also affected the success rate. Furthermore, we thought some factors such as individual physique, postoperative nursing level and the kind of instruments applied might also influence success rate.

Chest tube drainage referred to the placements of one or more intercostal drainage tubes connected to water seal system or suction system, which yielded maintenance until air leak disappeared and the chest $\mathrm{X}$-ray showed complete lung expansion (48). Generally speaking, chest tube drainages were usually applied for patients suffering 
from pneumothorax who should be admitted to hospital following the failure of needle aspiration (3). And other indications for chest tube drainage included hemothorax $(49,50)$, pleural effusion (51-53), pleural empyema (54,55), and major thoracic surgery (56-58). The approaches to insert chest tube drainage into body parts include axillary or anterior approach. Some studies had showed that axillary approach was the most favorable and effective approach, and the success rates could reach 66-97\% (26,59). However, no definite consensus on insertion methods had been reached. Chest tubes were generally divided into different types according to its sizes, such as small-bore $(<14 \mathrm{~F})$, large-bore ( $>20 \mathrm{~F})$ (3) and other sizes, which was associated with the extent of the pain. The pain brought by chest tube drainage was reckoned the biggest weakness and most of the patients experienced short-lasting but intense pain when the chest tube drainage was removed (60). Some trials found small-bore chest tube drainages had the similar success rate to larger drainage but being less painful (61). To manage the inevitable pain, one of the most common complications of chest tube drainage insertion, we needed more details to notice and perform. Nevertheless, there was no denying that chest tube drainage still played an important role in the treatment of spontaneous pneumothorax.

To the best of our knowledge, there has been several meta-analyses to focusing on the comparison of aspiration and chest tube drainage of pneumothorax. However, they haven't reached a definite consensus yet. Compared with preexisting articles, the advantages of our research are as follows. Firstly, we enrolled more RCTs with larger samples to reach a relatively convinced conclusion. Kaneda (7) performed a meta-analysis in 2013, but they only researched on four trials enrolling 331 patients regarding three parameters, and they didn't perform any subgroup analyses, sensitivity analyses or assessments of quality. While Zehtabchi et al. (18) only recruited three RCTs with 270 patients in total. Secondly, we performed strict inclusion and exclusion criteria. Kim et al.'s research (62), which published in 2017, didn't differentiate PSP and SSP without any subgroup analyses. While we researched on PSP but SSP, and included one recent study published in this year. Thirdly, the ethnicity of our included studies comprised Caucasian and Asian, and we made further subgroup analysis aimed to find potential difference. However, the previous articles only enrolled Caucasian except Sun' study (63) which was written by Chinese. Finally, we measured more parameters including one-week success rate, one-year recurrence rate, time of recurrence weeks, etc. Further analyses with respect to more outcomes would be beneficial to giving more comprehensive and possible recommendations for clinic practice.

In general, this analysis included as many RCTs as possible in order to make reliable conclusions. More importantly, we performed further subgroup analyses so that we could identify and solve some potential problems. In addition, we referred to amount of literatures to discuss some current controversies. We made a brief review about the two kinds of treatments, analyzed possible causes about the controversy and put forward the viewpoints carefully based on previous systematical analysis. However, some limitations still existed: (I) incomplete information. Some authors didn't report some essential information, such as the inclusion and exclusion criteria, randomization methods. Only limited articles could be used for some parameters; (II) the heterogeneity among included studies. We noticed that some included studies mentioned only first episode of pneumothorax, while others allowed recurrence. It is impossible to differentiate between these in the results, and we think it could be acceptable in this meta-analysis. And we assessed the risk of bias of each eligible studies, and found 4 of 7 studies reported unclear risk of concealment of allocation. But all the heterogeneity tests for each analysis were well accepted. And no significant results were found in subgroup analysis; (III) limited studies. Six studies with 458 participants in total were included in our analysis, however, only 2 studies with 109 patients were eligible for our analysis about immediate complete retraction rate. Thus, the limited sample might have effects on the final outcomes, and more large-sample RCTs are warranted.

\section{Conclusions}

In the light of this present research, it is necessary to apply needle aspiration to treat PSP for reducing hospitalization rate and hospital stay. However, the two treatments have no significant difference with respect to immediate success rate, one-year recurrence rate, one-week success rate, threemonth recurrence rate and complication rate.

\section{Acknowledgements}

Funding: This study was supported by the National Natural Science Foundation of China (Grant No. 81171320).

\section{Footnote}

Conflicts of Interest: The authors have no conflicts of interest to declare. 


\section{References}

1. Bintcliffe O, Maskell N. Spontaneous pneumothorax. Bmj 2014;348:g2928.

2. Wakai AP. Spontaneous pneumothorax. BMJ Clin Evid 2011;2011.

3. MacDuff A, Arnold A, Harvey J. Management of spontaneous pneumothorax: British Thoracic Society Pleural Disease Guideline 2010. Thorax 2010;65 Suppl 2:ii18-31.

4. Brims FJ, Maskell NA. Ambulatory treatment in the management of pneumothorax: a systematic review of the literature. Thorax 2013;68:664-9.

5. Korczynski P, Gorska K, Nasilowski J, et al. Comparison of Small Bore Catheter Aspiration and Chest Tube Drainage in the Management of Spontaneous Pneumothorax. Adv Exp Med Biol 2015;866:15-23.

6. Haynes D, Baumann MH. Management of pneumothorax. Semin Respir Crit Care Med 2010;31:769-80.

7. Kaneda H, Nakano T, Taniguchi Y, et al. Three-step management of pneumothorax: time for a re-think on initial management. Interactive Cardiovascular and Thoracic Surgery 2013;16:186-92.

8. Choi WI. Pneumothorax. Tuberc Respir Dis (Seoul) 2014;76:99-104.

9. Skaarup SH, Folkersen BH. Ultrasound-assisted aspiration of loculated pneumothorax: A new technique. J Clin Ultrasound 2016;44:326-30.

10. Bruschettini M, Romantsik O, Ramenghi LA, et al. Needle aspiration versus intercostal tube drainage for pneumothorax in the newborn. Cochrane Database Syst Rev 2016;(1):CD011724.

11. Pasquier M, Hugli O, Carron PN. Needle Aspiration of Primary Spontaneous Pneumothorax. N Engl J Med 2013;368:e24.

12. Desmettre T, Meurice JC, Mauny F, et al. [Comparison of simple aspiration versus standard drainage in the treatment of large primary spontaneous pneumothorax]. Rev Mal Respir 2011;28:336-43.

13. Brown SG, Ball EL, Macdonald SP, et al. Spontaneous pneumothorax; a multicentre retrospective analysis of emergency treatment, complications and outcomes. Intern Med J 2014;44:450-7.

14. Baumann MH, Strange C. Treatment of spontaneous pneumothorax: a more aggressive approach? Chest 1997;112:789-804.

15. Chen JS, Hsu HH, Tsai KT, et al. Salvage for unsuccessful aspiration of primary pneumothorax: thoracoscopic surgery or chest tube drainage? Ann Thorac Surg 2008;85:1908-13.

16. Delpy JP, Pages PB, Mordant P, et al. Surgical management of spontaneous pneumothorax: are there any prognostic factors influencing postoperative complications? Eur J Cardiothorac Surg 2016;49:862-7.

17. Park KT. The usefulness of two-port video-assisted thoracosopic surgery in low-risk patients with secondary spontaneous pneumothorax compared with open thoracotomy. Ann Thorac Med 2014;9:29-32.

18. Zehtabchi S, Rios CL. Management of emergency department patients with primary spontaneous pneumothorax: Needle aspiration or tube thoracostomy? Ann Emerg Med 2008;51:91-100,100.e1.

19. Astoul P. Editorial comment: Management of primary spontaneous pneumothorax: a plea for a mini-invasive approach. Eur J Cardiothorac Surg 2010;37:1135-6.

20. Devanand A, Koh MS, Ong TH, et al. Simple aspiration versus chest-tube insertion in the management of primary spontaneous pneumothorax: a systematic review. Respir Med 2004;98:579-90.

21. Janssen J, Cardillo G. Primary spontaneous pneumothorax: towards outpatient treatment and abandoning chest tube drainage. Respiration 2011;82:201-3.

22. Subotic D, Van Schil P. Spontaneous pneumothorax: remaining controversies. Minerva Chir 2011;66:347-60.

23. Baumann MH, Strange C, Heffner JE, et al. Management of spontaneous pneumothorax: an American College of Chest Physicians Delphi consensus statement. Chest 2001;119:590-602.

24. Wakai A, O'Sullivan RG, McCabe G. Simple aspiration versus intercostal tube drainage for primary spontaneous pneumothorax in adults. Cochrane Database Syst Rev 2007;(1):CD004479.

25. Andrivet P, Djedaini K, Teboul JL, et al. Spontaneous pneumothorax. Comparison of thoracic drainage vs immediate or delayed needle aspiration. Chest 1995;108:335-9.

26. Ayed AK, Chandrasekaran C, Sukumar M. Aspiration versus tube drainage in primary spontaneous pneumothorax: a randomised study. Eur Respir J 2006;27:477-82.

27. Harvey J, Prescott RJ. Simple aspiration versus intercostal tube drainage for spontaneous pneumothorax in patients with normal lungs. British Thoracic Society Research Committee. BMJ 1994;309:1338-9.

28. Ho KK, Ong ME, Koh MS, et al. A randomized controlled trial comparing minichest tube and needle aspiration in outpatient management of primary spontaneous 
pneumothorax. Am J Emerg Med 2011;29:1152-7.

29. Noppen M, Alexander P, Driesen P, et al. Manual aspiration versus chest tube drainage in first episodes of primary spontaneous pneumothorax: a multicenter, prospective, randomized pilot study. Am J Respir Crit Care Med 2002;165:1240-4.

30. Thelle A, Gjerdevik M, SueChu M, et al. Randomised comparison of needle aspiration and chest tube drainage in spontaneous pneumothorax. Eur Respir J 2017;49(4).

31. McDevitt J, Kelly M, Comber H, et al. A population-based study of hospital length of stay and emergency readmission following surgery for non-small-cell lung cancer. Eur J Cardiothorac Surg 2013;44:e253-9.

32. Goodney PP, Stukel TA, Lucas FL, et al. Hospital volume, length of stay, and readmission rates in high-risk surgery. Ann Surg 2003;238:161-7.

33. Parlak M, Uil SM, van den Berg JW. A prospective, randomised trial of pneumothorax therapy: manual aspiration versus conventional chest tube drainage. Respir Med 2012;106:1600-5.

34. Vazquez GH, Holtzman JN, Lolich M, et al. Recurrence rates in bipolar disorder: Systematic comparison of long-term prospective, naturalistic studies versus randomized controlled trials. Eur Neuropsychopharmacol 2015;25:1501-12.

35. Moubachir H, Zaghba N, Benjelloun H, et al. [Treatment of the first episode of spontaneous pneumothorax]. Rev Mal Respir 2016;33:789-93.

36. Annese V, Duricova D, Gower-Rousseau C, et al. Impact of New Treatments on Hospitalisation, Surgery, Infection, and Mortality in IBD: a Focus Paper by the Epidemiology Committee of ECCO. J Crohns Colitis 2016;10:216-25.

37. Uchida K. Pathophysiology and Therapeutic Approach of Pulmonary Aspiration. Masui 2016;65:13-22.

38. Chan SS. The role of simple aspiration in the management of primary spontaneous pneumothorax. J Emerg Med 2008;34:131-8.

39. Mukerjee A. Needle aspiration or chest drain for spontaneous pneumothorax. J Accid Emerg Med 1999;16:280-1.

40. Mendis D, El-Shanawany T, Mathur A, et al. Management of spontaneous pneumothorax: are British Thoracic Society guidelines being followed? Postgrad Med J 2002;78:80-4.

41. Chan SS, Lam PK. Simple aspiration as initial treatment for primary spontaneous pneumothorax: results of 91 consecutive cases. J Emerg Med 2005;28:133-8.

42. Aguinagalde Valiente B, Zabaleta Jimenez J, Busca
Ostolaza P, et al. Needle aspiration is safe and effective for treating primary spontaneous pneumothorax. Emergencias 2013;25:111-5.

43. Nikolic MZ, Lok LS, Mattishent K, et al. Noninterventional statistical comparison of BTS and CHEST guidelines for size and severity in primary pneumothorax. Eur Respir J 2015;45:1731-4.

44. Kelly AM, Clooney M. Deviation from published guidelines in the management of primary spontaneous pneumothorax in Australia. Intern Med J 2008;38:64-7.

45. Nishiuma T, Ohnishi H, Katsurada N, et al. Evaluation of simple aspiration therapy in the initial treatment for primary spontaneous pneumothorax. Internal Medicine 2012;51:1329-33.

46. Kuester JR, Frese S, Stein RM, et al. Treatment of primary spontaneous pneumothorax in Switzerland: results of a survey. Interact Cardiovasc Thorac Surg 2006;5:139-44.

47. Courtney PA, McKane WR. Audit of the management of spontaneous pneumothorax. Ulster Med J 1998;67:41-3.

48. Aguinagalde B, Zabaleta J, Fuentes M, et al. Percutaneous aspiration versus tube drainage for spontaneous pneumothorax: systematic review and meta-analysis. Eur J Cardiothorac Surg 2010;37:1129-35.

49. Stiles PJ, Drake RM, Helmer SD, et al. Evaluation of chest tube administration of tissue plasminogen activator to treat retained hemothorax. Am J Surg 2014;207:960-3.

50. Yi JH, Liu HB, Zhang M, et al. Management of traumatic hemothorax by closed thoracic drainage using a central venous catheter. J Zhejiang Univ Sci B 2012;13:43-8.

51. Epstein E, Jayathissa S, Dee S. Chest tube drainage of pleural effusions--an audit of current practice and complications at Hutt Hospital. N Z Med J 2012;125:26-35.

52. Lin CH, Lin WC, Chang JS. Comparison of pigtail catheter with chest tube for drainage of parapneumonic effusion in children. Pediatr Neonatol 2011;52:337-41.

53. Rahman NM, Pepperell J, Rehal S, et al. Effect of Opioids vs NSAIDs and Larger vs Smaller Chest Tube Size on Pain Control and Pleurodesis Efficacy Among Patients With Malignant Pleural Effusion: The TIME1 Randomized Clinical Trial. JAMA 2015;314:2641-53.

54. Cafarotti S, Dall'Armi V, Cusumano G, et al. Small-bore wire-guided chest drains: safety, tolerability, and effectiveness in pneumothorax, malignant effusions, and pleural empyema. J Thorac Cardiovasc Surg 2011;141:683-7.

55. Shoseyov D, Bibi H, Shatzberg G, et al. Short-term course and outcome of treatments of pleural empyema in pediatric patients: repeated ultrasound-guided needle thoracocentesis vs chest tube drainage. Chest 
2002;121:836-40.

56. Filosso PL, Sandri A, Guerrera F, et al. Management of Chest Drains After Thoracic Resections. Thorac Surg Clin 2017;27:7-11.

57. Tanaka M, Sagawa M, Usuda K, et al. Postoperative drainage with one chest tube is appropriate for pulmonary lobectomy: a randomized trial. Tohoku J Exp Med 2014;232:55-61.

58. Zhou D, Deng XF, Liu QX, et al. Single chest tube drainage is superior to double chest tube drainage after lobectomy: a meta-analysis. J Cardiothorac Surg 2016;11:88.

59. Klopp M, Hoffmann H, Dienemann H. How to do - the chest tube drainage. Dtsch Med Wochenschr

Cite this article as: Wang C, Lyu M, Zhou J, Liu Y, Ji Y. Chest tube drainage versus needle aspiration for primary spontaneous pneumothorax: which is better? J Thorac Dis 2017;9(10):40274038. doi:10.21037/jtd.2017.08.140
2015;140:339-42.

60. Owen S, Gould D. Underwater seal chest drains: the patient's experience. J Clin Nurs 1997;6:215-25.

61. Clementsen P, Evald T, Grode G, et al. Treatment of malignant pleural effusion: pleurodesis using a small percutaneous catheter. A prospective randomized study. Respir Med 1998;92:593-6.

62. Kim MJ, Park I, Park JM, et al. Systematic review and meta-analysis of initial management of pneumothorax in adults: Intercostal tube drainage versus other invasive methods. PLoS One 2017;12:e0178802.

63. Sun Z, Cao Z, Fu H. Meta-analysis of needle aspiration versus chest tube drainage in primary spontaneous pneumothorax. Chinese General Practice 2012;15:665-7. 